\title{
Leukaemic phase of mantle zone (intermediate) lymphoma: its characterisation in 11 cases
}

\author{
M S POMBO DE OLIVEIRA, * E S JAFFE, D CATOVSKY*
}

\begin{abstract}
From the *Department of Haematology and Cytogenetics, The Royal Marsden Hospital, London, and the Department of Pathology, National Cancer Institute, Bethesda, Maryland, United States of America
\end{abstract}

SUMMARY Sixteen patients presented with B cell leukaemia (white cell count 26-269 $\times 10^{9} / 1$ ) which could not be classified as chronic lymphocytic (CLL), prolymphocytic leukaemia, or follicular 용 lymphoma in leukaemic phase. Eleven patients (10 men, one woman) corresponded histologically to intermediate (INT) or mantle zone lymphoma, and five, with less well defined features, were 6 designated small lymphocytic lymphoma with cleaved cells. The blood films showed a pleomorphic picture with lymphoid cells of predominantly medium size with nuclear irregularities and clefts. The membrane phenotype of the circulating cells showed strong immunoglobulin staining and reactivity with CD5 and FMC7 in all cases tested; CD10 was positive in six out of nine cases. The membrane $\vec{c}$ phenotype of two of the five cases of small lymphocytic lymphoma was close to those of B-CLL and three resembled INT lymphoma. Bone marrow trephine biopsy specimens showed a diffuse pattern of infiltration in INT lymphoma. The median survival of these patients was less than two years, suggesting that a leukaemic presentation is associated with poor prognosis. By combining data from histology, membrane markers, and peripheral blood morphology, the leukaemic phase of typical INकु lymphoma can be defined in most cases.

Intermediate (INT) lymphoma or mantle zone lymphoma is a form of non-Hodgkin's lymphoma (NHL) characterised by a predominantly diffuse or vaguely nodular proliferation of atypical small lymphoid cells effacing the nodal architecture.' This lymphoma has not been included specifically in any of the major classification schemes. In the Working Formulation, ${ }^{2}$ however, most cases would be assigned to the category of small cleaved type with an intermediate prognostic grade, and in the Kiel classification ${ }^{3}$ these would be included in the centrocytic type of NHL.

INT lymphoma is a B cell tumour with a mature phenotype and a characteristic expression of the p67 antigen (CD5). ${ }^{45}$ So far, no detailed study of the leukaemic manifestations of this lymphoma has been published. This may be due to the rarity of this phenomenon or perhaps because some of these cases are misdiagnosed as chronic lymphocytic leukaemia (CLL). This study reports the clinical, morphological, and immunological findings of 11 cases of INT (mantle zone) lymphoma in leukaemic phase which presented with a high white cell count. We were particularly interested to identify any clinical or pathological features which might be of help in the

Accepted for publication 12 April 1989 differential diagnosis between this disorder and CLL, or its variants, and other NHL in leukaemic phase such as follicular lymphoma. ${ }^{6} \mathrm{~A}$ comparison was made with some cases which exhibited cytological atypia in excess of that seen in CLL and in which the possible diagnosis of INT lymphoma was suspected.

\section{Material and methods}

Diagnostic material from 16 patients with $B$ lymphoproliferative disorders in frank leukaemic phase was included in this study. The patients were selected over a period of three years, between 1985 and 1987, among cases of chronic B cell leukaemias submitted to our 은 laboratory for marker studies. These cases were referred with a diagnosis of CLL or prolymphocytic leukaemia (B-PLL) or of lymphoid leukaemia of an unspecified nature.

The morphological detail of the circulating cells was $N$ studied by light microscopy on peripheral blood films stained with May-Grüwald Giemsa. Histological sections stained with haematoxylin and eosin from the following affected tissues were also reviewed: lymph nodes $(n=9)$; spleen $(n=3)$; bone marrow trephine $\stackrel{?}{?}$ biopsy specimens $(n=16)$.

Immunological markers were carried out on peri- 
pheral blood mononuclear cell suspensions as described previously. ${ }^{5}$ The following tests were carried out: (i) formation of rosettes with mouse (M) and sheep (E) erythrocytes; (ii) surface immunoglobulins (SmIg) by direct immunofluorescence with an FITCconjugated $\mathrm{F}(\mathrm{ab}) 2$ fragment of goat anti-human $\kappa$ and $\lambda$ (Cappel); and (iii) leucocyte differentiation antigens detected by indirect immunofluorescence with a panel of monoclonal antibodies - namely, GRBI, anti-class II MHC antigen; UCHT2 (CD5), anti-p67; FMC7 (Seralab), which recognises a subpopulation of $\mathbf{B}$ lymphocytes (non-clustered); J5 (Coulter), antiCALLA (CD10); B4 (Coulter) pan-B, anti-p95 (CD19); CLB/BLy1, anti-p135 (CD22). Second layer reagents consisted of a FITC-conjugated $F(a b) 2$ fragment of goat anti-mouse IgG or IgM. The proportion of positive cells was determined by fluorescence microscopy. The intensity of immunofluorescence was also assessed by readings on a FACS analyser (BectonDickinson) in some of the samples.

\section{Results}

The clinical and haematological data of 11 patients in whom the diagnosis of INT NHL was confirmed histologically and five others in whom the diagnosis was suspected on peripheral blood findings but was not substantiated by histological analysis are summarised in table 1. All of them presented with leukaemia and a raised white cell count. There were 14 men and two women (ratio 7:1) with a mean age of 66 years, presenting with symptoms of weakness or tiredness and single or multiple enlarged lymph nodes. Physical examination showed that all but two patients had widespread lymphadenopathy, 14 had splenomegaly with palpable spleens from 2 to $10 \mathrm{~cm}$ below the costal margin, and seven had moderate hepatomegaly. The leukaemic process was characterised by a white cell count ranging from 26 to $269 \times 10^{9} / 1$ with a median of $45 \times 10^{9} / 1$, and with lymphoid cells accounting for 80 to $93 \%$ of the differential count. Information on treatment was obtained from nine patients; five were being treated with chlorambucil and prednisolone, three were receiving combinations including anthracyclines (CHOP) and one patient (case 7) was not being treated. The survival of these patients was variable, ranging from six to 100 months with a median of 27 months.

\section{MOR PHOLOGICAL FEATURES SEEN ON BLOOD FILMS}

In all 16 cases the lymphocytes had a fairly pleomorphic appearance and consisted of a mixture of small, medium, and large cells (fig 1). In cases 1-5 the cells were predominantly of medium size (diameter greater than two erythrocytes) with a visible amount of cytoplasm, round nucleus, moderately coarse chromatin and conspicuous nucleoli. Some cells showed nuclear irregularities, and in some the nuclei were cleaved (figs 2 and 3). In six cases (cases 6-11) the morphological detail was more pleomorphic with both medium and large size cells, a moderate amount of cytoplasm, and a nucleus which was round, angular, or cleaved with immature chromatin and one or two visible nucleoli, sometimes resembling prolymphocytes (fig 4). In cases 12-16 the cells were more regular in size and were predominantly small with a regular round nucleus, some nuclear clefts, and clumped chromatin with small or prominent nucleoli in some of them (fig 5). Table 2 compares the features of the circulating lymphocytes of the cases analysed here with those of typical CLL cells, described elsewhere. ${ }^{6}$ Overall, the cases in this series showed consistent cell size heterogeneity and cellular pleomorphism, while

Table 1 Clinical and laboratory features

\begin{tabular}{|c|c|c|c|c|c|c|c|c|c|}
\hline \multirow{2}{*}{$\begin{array}{l}\text { Case } \\
\text { No }\end{array}$} & & \multirow[b]{2}{*}{ Sex } & \multirow{2}{*}{$\begin{array}{l}\text { Haemoglobin } \\
(\mathrm{g} / \mathrm{dl})\end{array}$} & \multirow{2}{*}{$\begin{array}{l}\text { White } \\
\text { cells } \\
(\times 10 / l)\end{array}$} & \multirow[b]{2}{*}{ Platelets } & \multirow[b]{2}{*}{ Lymph nodes } & Spleen & Liver & \multirow{2}{*}{$\begin{array}{l}\text { Survival } \\
\text { (months) }\end{array}$} \\
\hline & & & & & & & \multicolumn{2}{|c|}{ ( $\mathrm{cm}$ below costal margin) } & \\
\hline $\begin{array}{r}1 \\
2 \\
3 \\
4 \\
5 \\
6 \\
7 \\
8 \\
9 \\
10 \\
11 \\
12 \\
13 \\
14 \\
15 \\
16\end{array}$ & $\begin{array}{l}65 \\
35 \\
63 \\
72 \\
77 \\
84 \\
61 \\
65 \\
66 \\
66 \\
65 \\
49 \\
55 \\
72 \\
62 \\
63\end{array}$ & $\begin{array}{l}\mathbf{M} \\
\mathbf{M} \\
\mathbf{M} \\
\mathbf{M} \\
\mathbf{M} \\
\mathbf{F} \\
\mathbf{M} \\
\mathbf{M} \\
\mathbf{M} \\
\mathbf{M} \\
\mathbf{M} \\
\mathbf{M} \\
\mathbf{M} \\
\mathbf{M} \\
\mathbf{M} \\
\mathbf{F}\end{array}$ & $\begin{array}{r}9 \cdot 6 \\
12 \cdot 0 \\
12 \cdot 0 \\
7 \cdot 0 \\
7 \cdot 8 \\
12 \cdot 0 \\
14 \cdot 0 \\
12 \cdot 0 \\
10 \cdot 0 \\
7 \cdot 9 \\
12 \cdot 0 \\
11 \cdot 0 \\
14 \cdot 0 \\
12 \cdot 0 \\
11 \cdot 0 \\
10 \cdot 0\end{array}$ & $\begin{array}{r}130 \\
45 \\
60 \\
252 \\
269 \\
43 \\
35 \\
25 \\
40 \\
70 \\
40 \\
95 \\
65 \\
40 \\
48 \\
60\end{array}$ & $\begin{array}{r}150 \\
200 \\
200 \\
150 \\
97 \\
180 \\
300 \\
180 \\
90 \\
200 \\
200 \\
100 \\
250 \\
200 \\
115 \\
130\end{array}$ & $\begin{array}{l}\text { Generalised } \\
\text { Axillary } \\
\text { Generalised } \\
\text { Not palpable } \\
\text { Generalised } \\
\text { Axillary } \\
\text { Generalised } \\
\text { Generalised } \\
\text { Axillary } \\
\text { Not palpable } \\
\text { Generalised } \\
\text { Cervical } \\
\text { Generalised } \\
\text { Generalised } \\
\text { Generalised } \\
\text { Not palpable }\end{array}$ & $\begin{array}{l}7 \\
6 \\
\text { Not palpable } \\
8 \\
6 \\
\text { Not palpable } \\
\text { Not palpable } \\
6 \\
2 \\
\text { Not palpable } \\
8 \\
4 \\
3 \\
8 \\
8 \\
10\end{array}$ & $\begin{array}{l}2 \\
2 \\
\text { Not palpable } \\
\text { Not palpable } \\
3 \\
\text { Not palpable } \\
\text { Not palpable } \\
3 \\
\text { Not palpable } \\
\text { Not palpable } \\
2 \\
\text { Not palpable } \\
2 \\
\text { Not palpable } \\
3 \\
3\end{array}$ & $\begin{array}{l}48 \text { alive } \\
9 \\
6 \\
12 \\
36 \text { alive } \\
36 \text { alive } \\
19 \\
36 \text { alive } \\
16 \text { alive } \\
24 \text { alive } \\
90\end{array}$ \\
\hline
\end{tabular}




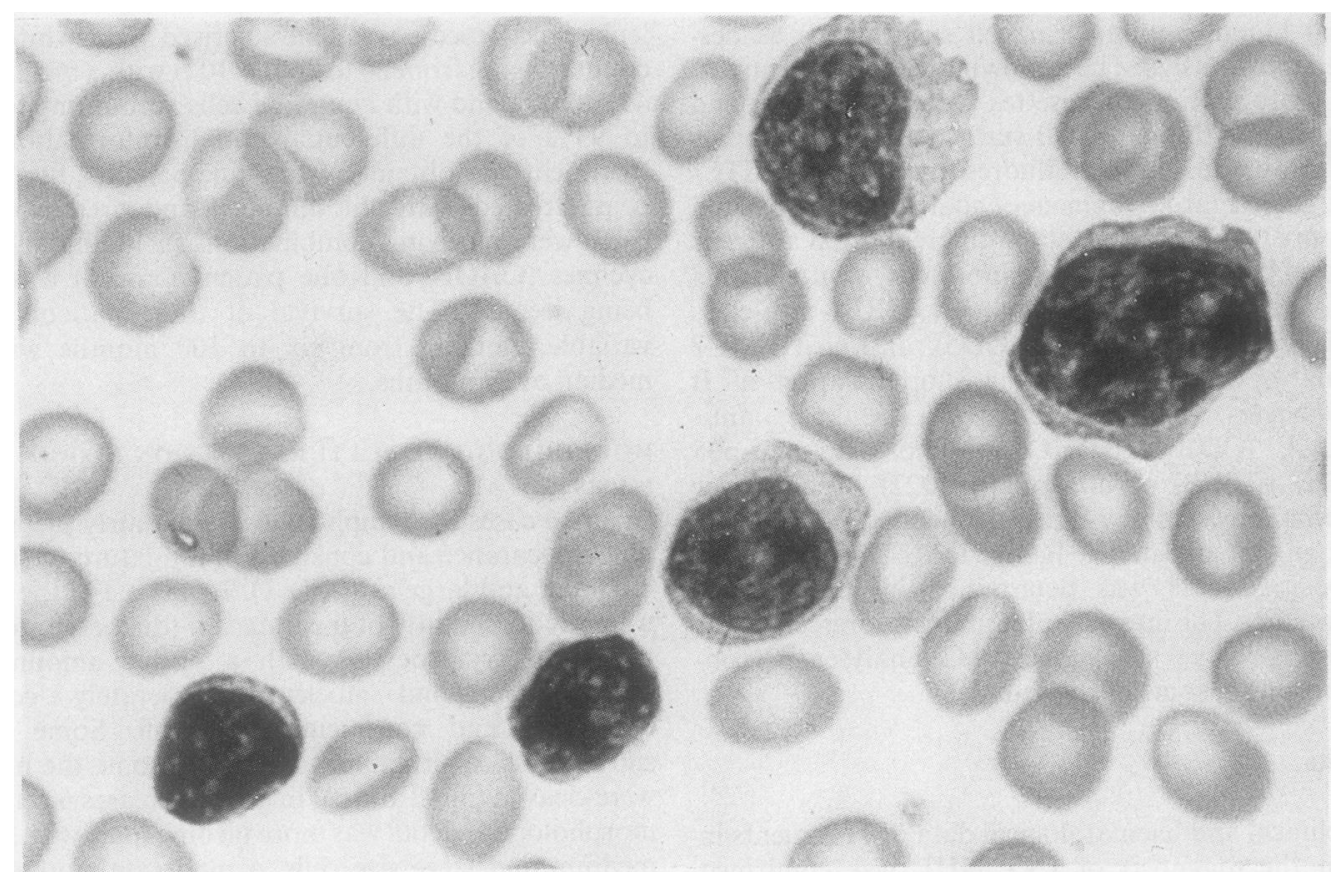

Fig 1 Peripheral blood film from a case of INT NHL showing the variability in cell size of the circulating cells.

lymphocytes of CLL differed from them mainly on account of their monomorphic features and small size with scanty cytoplasm and coarse nuclear chromatin. Fewer than $10 \%$ of CLL cells have a visible nucleolus and these have morphology typical of prolymphocytes. The cells from the cases described here also differed from the circulating lymphocytes of follicular lymphoma presenting in leukaemic phase which have condensed nuclear chromatin and an angular nucleus with deep clefts (table 2).

\section{HISTOLOGICAL FEATURES}

The histological materiai showed infiltration by atypical lymphoid cells with a diffuse or vaguely nodular pattern. Two related types of NHL were diagnosed in this group of cases. Cases 1-11 fulfilled the criteria for a diagnosis of lymphocytic lymphoma of intermediate differentiation (INT NHL) or mantle zone NHL, and cases 12-16 were called small lymphocytic lymphoma with cleaved cells. In the typical INT cases the process was characterised by architectural effacement by a diffuse or vaguely nodular infiltrate. Residual naked germinal centres were prominent. The infiltrating lymphoid cells had moderately condensed nuclear chromatin, inconspicuous small basophilic nucleoli, and varying degrees of nuclear irregularity. Admixed single epithelioid histiocytes with pale eosinophilic cytoplasm were often seen. In some cases cells with finely distributed rather. than clumped chromatin were prominent (figs 6-8) Bone marrow biopsy specimens from these 11 cases showed pronounced infiltration with a diffuse pattern in the intramedullary spaces and a mixture of small and medium size lymphocytes with moderately clumped chromatin, variable numbers of cleaved cells, and the presence of pink epithelioid histiocytes. Five cases (cases 12-16), designated lymphocytic lymphoma with cleaved cells, were characterised in tissue sections (lymph node, spleen or bone marrow trephine biopsy specimens) by diffuse infiltration with predominantly small lymphocytes with condensed nuclear chromatin and sparse indistinct cytoplasm. Pseudofollicular growth centres were prominent in these cases which were composed of an ill defined collection of larger lymphoid cells with prominent central, often eosinophilic, nucleoli admixed with smaller cells (figs 9-11). The larger cells had vesicular nuclei, and a continuous spectrum in cell size was present within the growth centres. At high power, cleaved cells were identified among the small round lymphoid cells and these were similar to those observed in the cases of INT NHL.

\section{MEMBRANE MARKERS}

The membrane phenotype of circulating lymphocytes in the 11 cases of INT NHL and the five cases of 0 lymphocytic lymphoma are shown in table 3 . All 16 

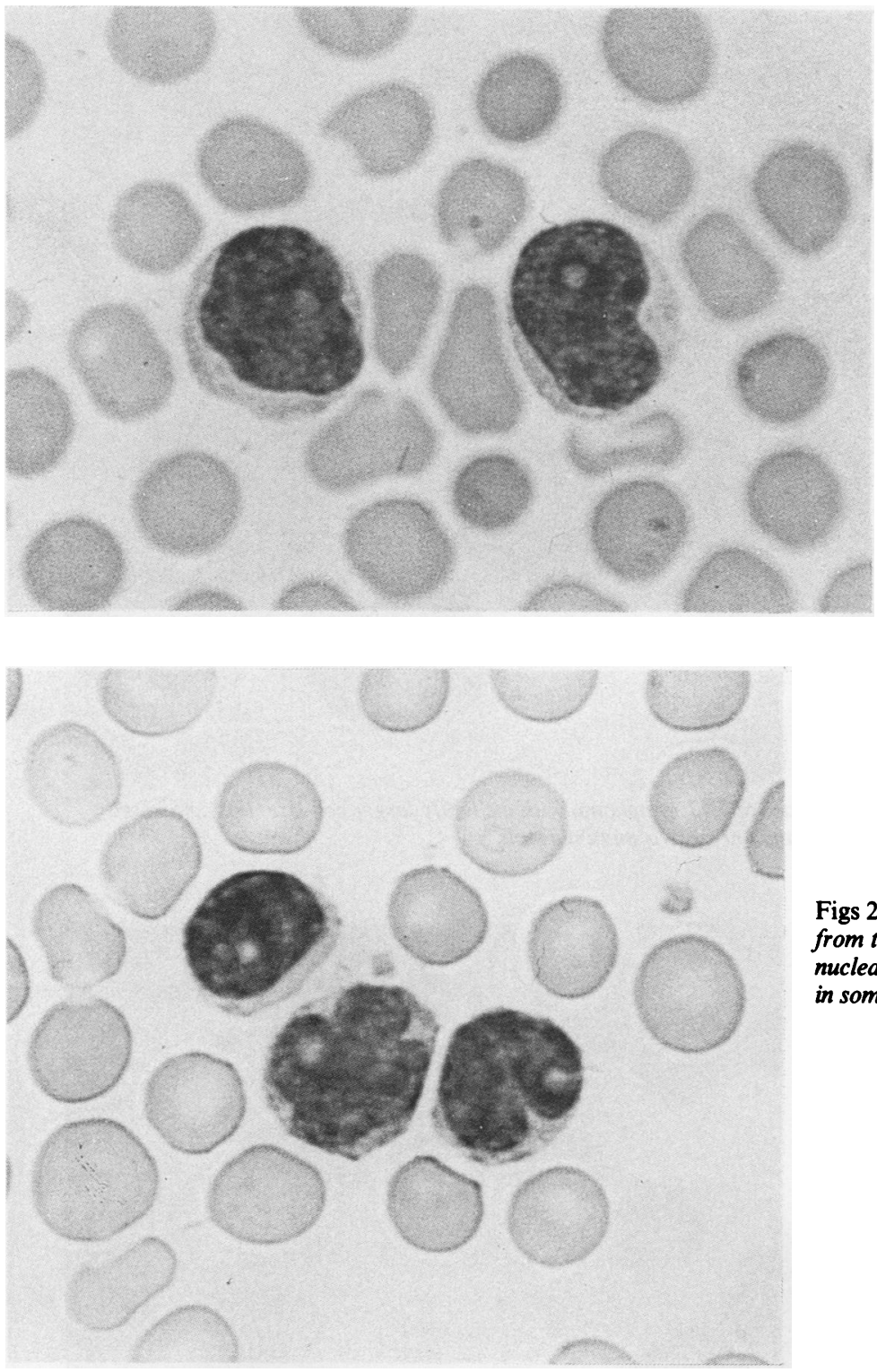

Figs 2 and 3 Medium size lymphocytes from two cases of INT NHL with irregular nuclear outline and moderate nuclear clefts in some cells.

cases expressed surface immunoglobulin (SmIg) with strong staining intensity; in four out of 12 cases tested, two of INT NHL (cases 1 and 9) and two others (cases 12 and 14), the cells formed M-rosettes. The p67 antigen (CD5) was shown in the cells of all 16 cases. In 11 out of the 16 cases (including cases from both groups) $35 \%$ to $70 \%$ of the cells reacted with the monoclonal antibody FMC7. Eight of the 14 cases were positive for $\mathrm{CD} 10$, with a slightly higher proportion of positive cases among the group with INT lymphoma. CD19 and HLA-Dr were similarly positive in all the cases tested. None of the cases of INT group had a typical CLL phenotype (mouse rosettes $\mathbf{5 0} \%$, weak SmIg, CD5 positive, FMC7 $<30 \%$ and CD10 negative) but in the small lymphocytic group two cases (12 and 13) had phenotype close 


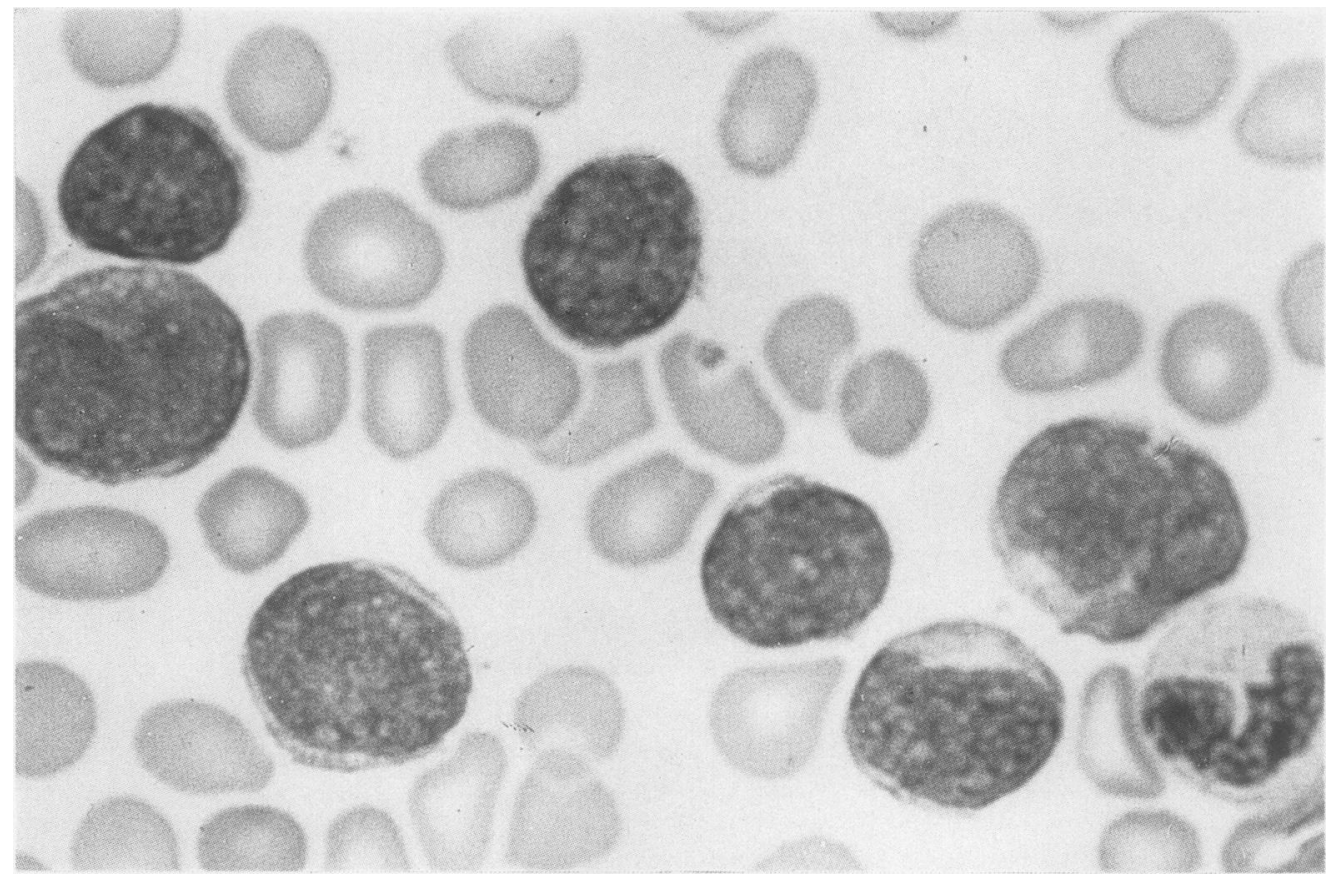

Fig 4 Peripheral blood film from another case of INT lymphoma with a slightly larger cell size, less condensed nuclear chromatin than the cells in figs 1-3, and one or two small nucleoli.

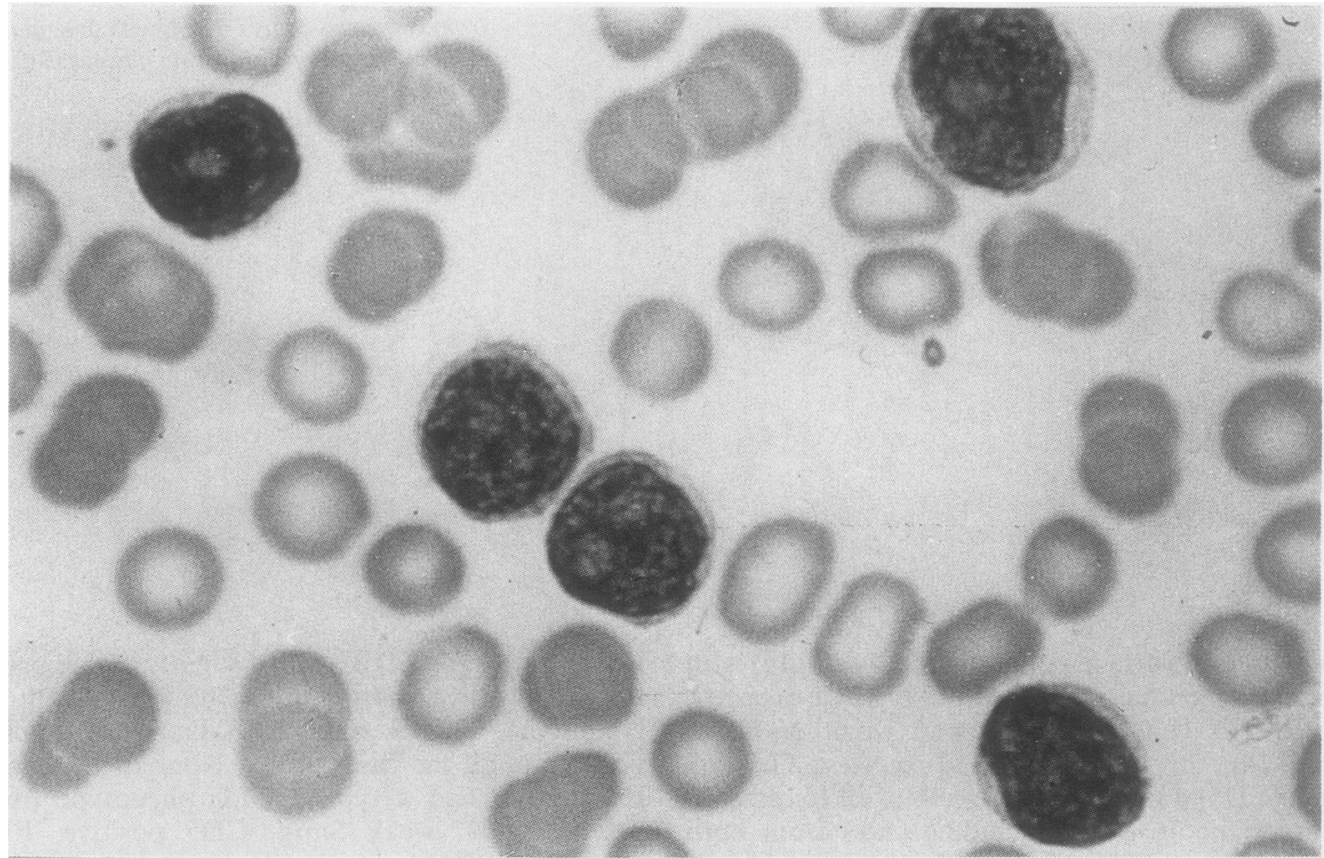

Fig 5 Peripheral blood film from a case of suspected INT lymphoma but reclassified as small lymphocytic with cleaved cells, showing lymphocytes of small size and some with a slightly irregular outline and prominent nucleolus. 
Table 2 Morphological features of circulating lymphocytes in two types of NHL and CLL

\begin{tabular}{llll}
\hline Features & INT (mantle zone) lymphoma* & Typical CLL & Follicular lymphoma \\
\hline Cell size & $\begin{array}{l}\text { Pleomorphic with small, medium and large } \\
\text { cells }\end{array}$ & $\begin{array}{l}\text { Monomorphic, 1-2 red blood } \\
\text { cells }\end{array}$ & $\begin{array}{c}\text { Less or equal to red blood } \\
\text { cells } \\
\text { Very scanty }\end{array}$ \\
$\begin{array}{l}\text { Cytoplasm } \\
\text { Chromatin }\end{array}$ & $\begin{array}{l}\text { Moderately coarse, some cells have immature } \\
\text { (fine) chromatin }\end{array}$ & $\begin{array}{l}\text { Scanty but visible } \\
\text { Clumped, coarse, in blocks }\end{array}$ & Condensed, single block \\
Nucleus & $\begin{array}{l}\text { Mixture of round, angular, cleaved; slight } \\
\text { nuclear irregularities }\end{array}$ & Shallow indentations if any & $\begin{array}{c}\text { Clefts; sharp angular deep } \\
\text { indentations }\end{array}$ \\
$\begin{array}{l}\text { Nucleoli } \\
\text { Smudge cells }\end{array}$ & $\begin{array}{l}\text { Small central in > 30\% } \\
\text { Absent or very few }\end{array}$ & $<10 \%$ prolymphocytes & Abo, blastic \\
\hline
\end{tabular}

*Includes cases described by Lennert as centrocytic NHL. ${ }^{3}$

to that of CLL, except for the positivity of FMC7 and strong SmIg. No clinically important differences were apparent between the two groups of cases studied with respect to other immunological markers.

\section{Discussion}

This group of 16 could not be classified easily by conventional morphological criteria ${ }^{6}$ as having either B-CLL, ${ }^{7}$ B-prolymphocytic leukaemia, ${ }^{8}$ or follicular lymphoma in leukaemic phase. ${ }^{6}$ Based on the histological appearance we identified 11 of these cases as having INT (mantle zone) NHL and five as small lymphocytic lymphoma with cleaved cells. Although clinically, all these cases resembled CLL, laboratory features showed major differences, notably the peri- pheral blood morphology, the membrane phenotype, and histological patterns.

INT lymphoma is often seen in middle aged to elderly men and presents with lymph node enlargement, splenomegaly, and bone marrow disease. ${ }^{9}$ Only a few cases presenting with a florid leukaemic phase have been reported. ${ }^{49}$ The highest lymphocyte count previously recorded is $32.9 \times 10^{9} / 1$. In our cases the white cell count ranged from 26 to $269 \times 10^{9} / 1$ and the circulating lymphocytes were predominantly a mixture of small, medium, and large size cells with a visible amount of cytoplasm and a round nucleus with angular and often cleaved features; nucleoli were conspicuously seen in a relatively high proportion of cells. Melo et al described a group of 84 patients among a series of 300 that were designated CLL with

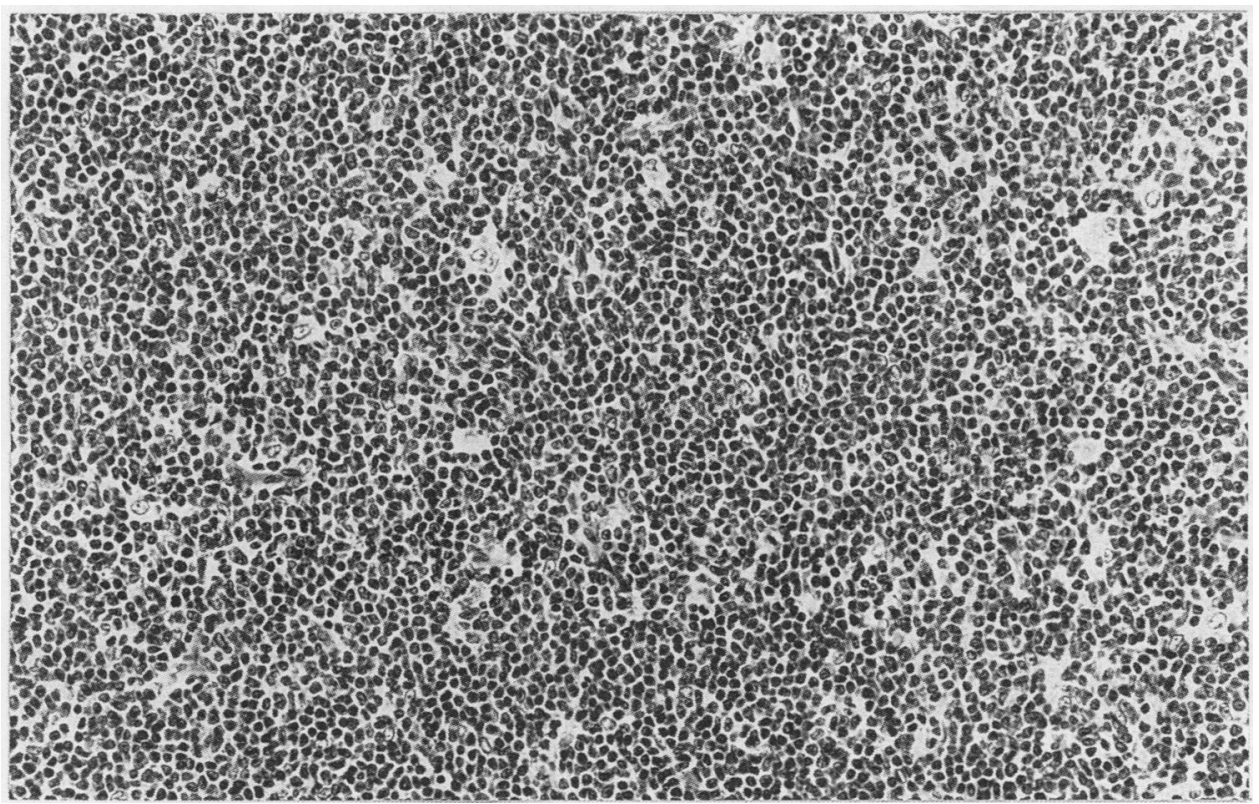

Fig 6 Lymph node sections from a case of INT lymphoma (case 8). At low power, the process is predominantly diffuse. The lymph node is effaced by a uniform cell population. Scattered among the neoplastic cells are epithelioid histiocytes with pale eosinophilic cytoplasm. 


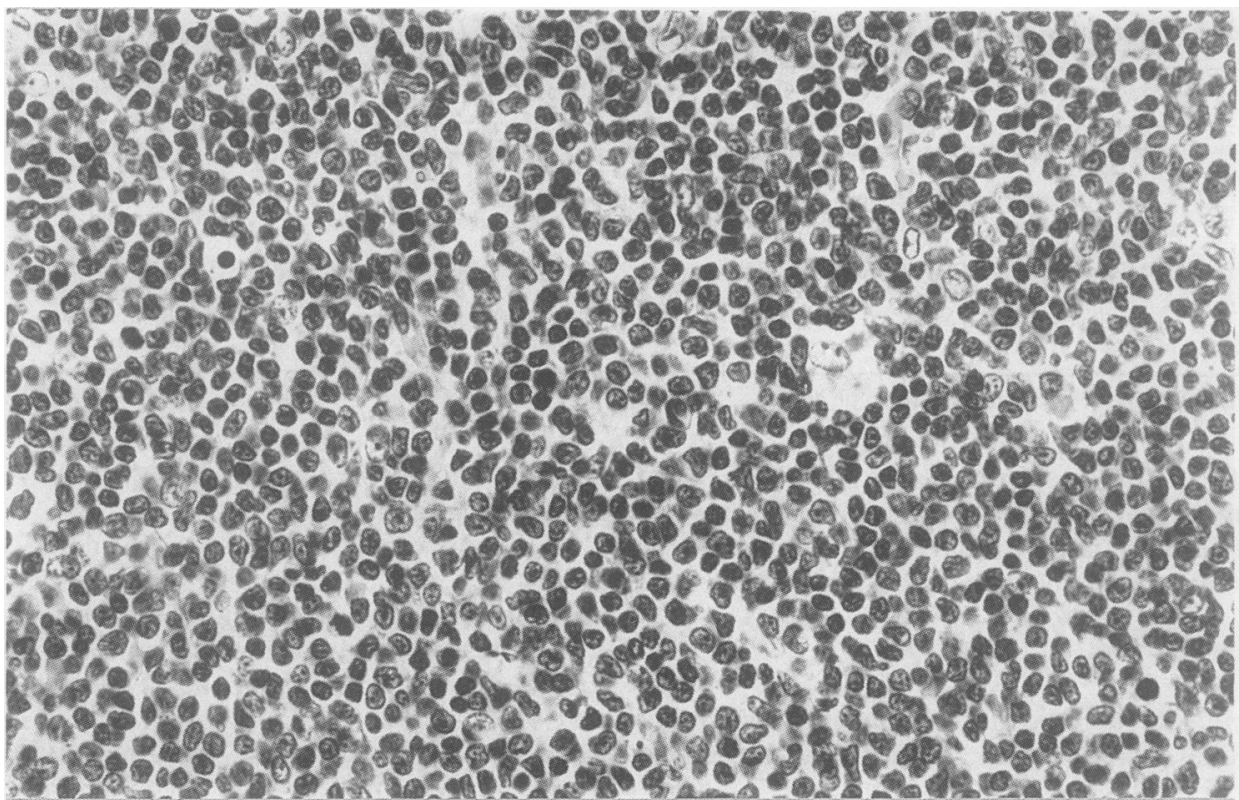

Fig 7 At higher power, scattered epithelioid histiocytes among atypical lymphoid cells. The cells have condensed nuclear chromatin.

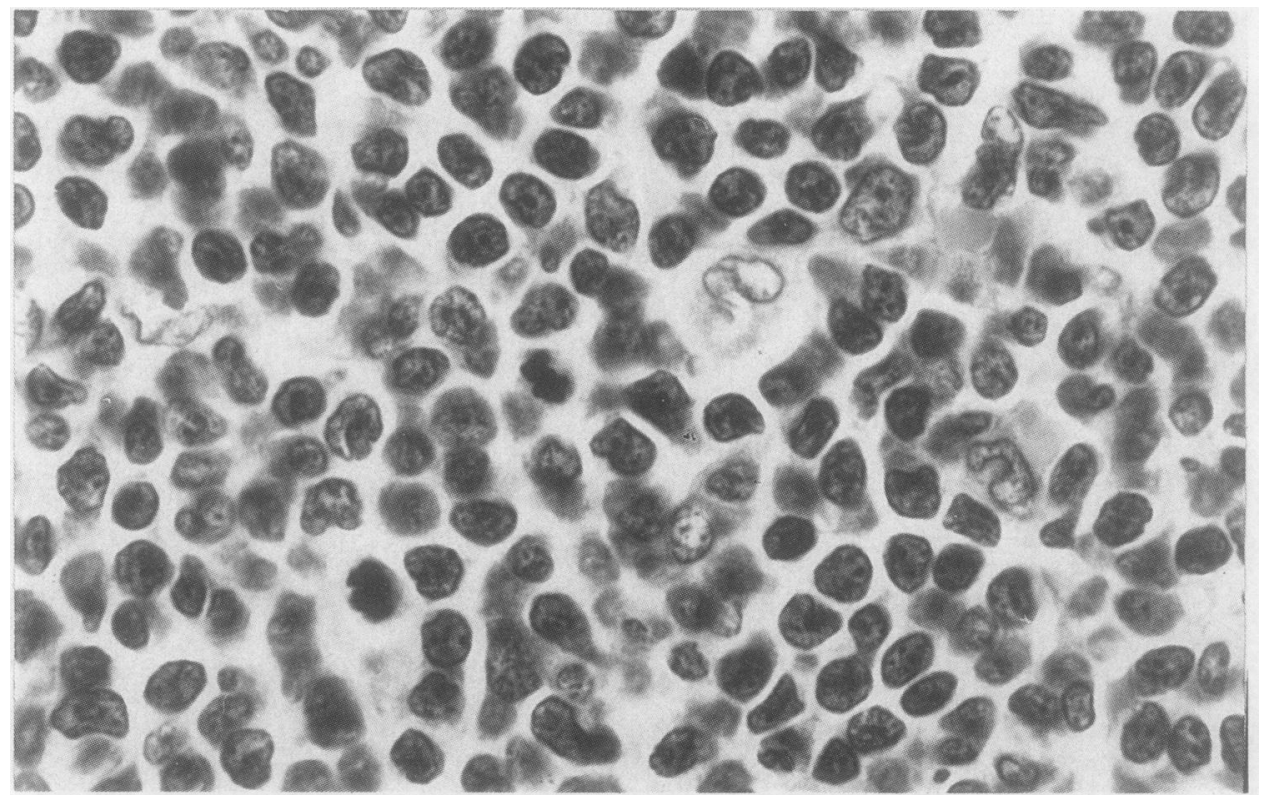

Fig 8 At higher power, atypical lymphoid cells. The cells have condensed nuclear chromatin and inconspicuous small basophilic nucleoli. In this field two mitotic figures are seen. The cells show varying degrees of nuclear irregularity and cleavage. A single epithelioid histiocyte can be identified. The histiocyte has an indented nucleus with finely distributed sparse chromatin and abundant pale eosinophilic cytoplasm. The admixed epithelioid histiocytes do not usually contain karyorrhectic debris. 


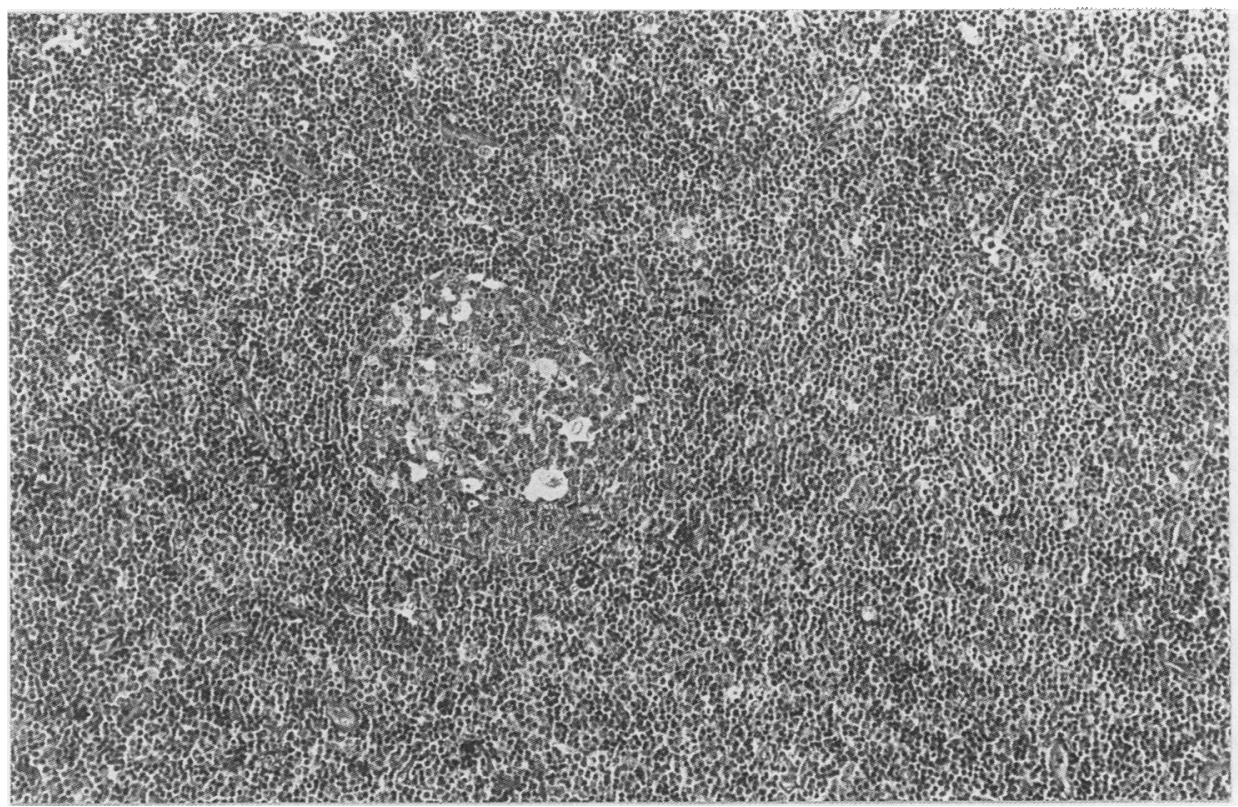

Figs 9 to 11 Lymph node sections from case 12, malignant lymphoma, small lymphocytic type with cleaved cells.

Fig 9 At low power, diffuse infiltration of the lymph node is seen with sparing of residual naked germinal centres. The latter can be seen in both small lymphocytic malignancies and INT lymphocytic lymphoma.

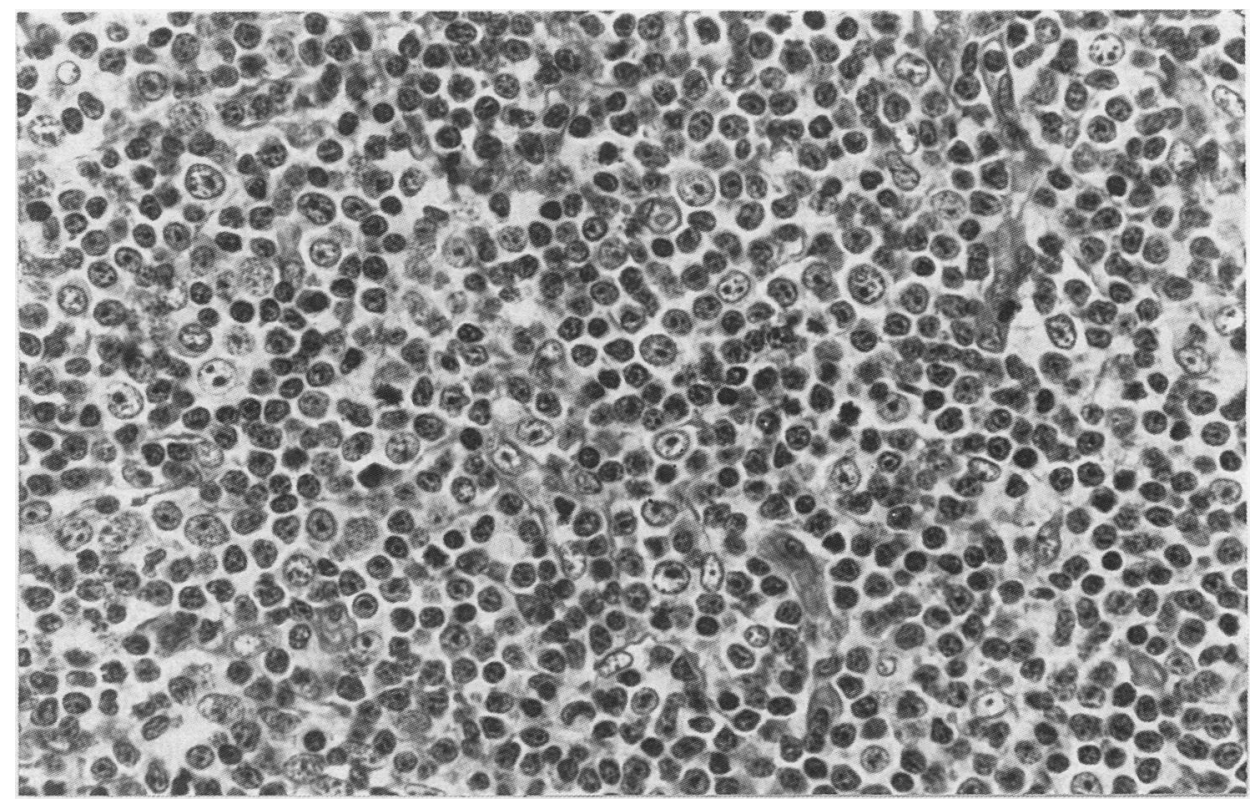

Fig 10 A pseudofollicular growth centre composed of an ill defined collection of large lymphoid cells with condensed nuclear chromatin. There is no distinct follicular pattern. 


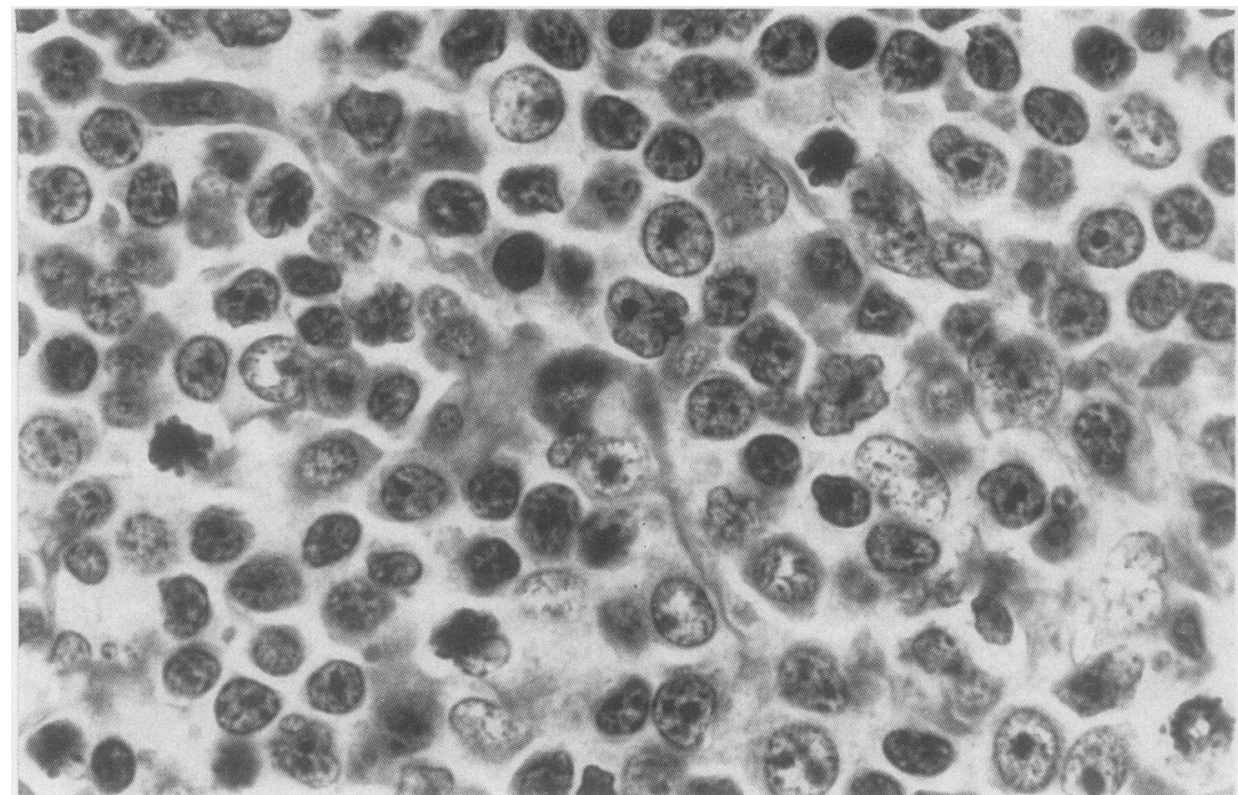

Fig 11 At higher power, individual cells with cleaved nuclei are admixed with small round lymphoid cells with condensed nuclear chromatin. The cleaved cells are similar in appearance to those observed in lymphocytic lymphomas of INT differentiation.

Table 3 Immunological markers of circulating lymphocytes in two groups of cases*

\begin{tabular}{llll}
\hline & $\begin{array}{l}\text { Membrane } \\
\text { markers }\end{array}$ & $\begin{array}{l}\text { INT } \\
\text { lymphoma } \\
\text { (cases 1-11) }\end{array}$ & $\begin{array}{l}\text { "Small } \\
\text { lymphocytic" } \\
\text { (cases 12-16) }\end{array}$ \\
\hline SmIg† & $\mathrm{K}$ & 5 & 3 \\
M-rosettes & $\mathbf{2} 50 \%$ & 6 & 2 \\
CD5 & $0-50 \%$ & 2 & 1 \\
& $>50 \%$ & 7 & 2 \\
FMC7 & $30-49 \%$ & 9 & 3 \\
& $>70 \%$ & 2 & 2 \\
CD10 & $35-40 \%$ & 6 & 1 \\
& $0 \%$ & 3 & 1 \\
CD19 & $40-90 \%$ & 0 & 2 \\
& $16-39 \%$ & 3 & 1 \\
& $0 \%$ & 3 & 1 \\
\hline
\end{tabular}

*Some tests were not performed in all cases; antibodies to class II MHC were positive in all cases.

†Strong staining in all cases.

an increase in prolymphocytes (CLL/PL), selected on morphological grounds by the presence in peripheral blood films of small lymphocytes and a proportion of prolymphocytes $\left(10 \%\right.$ to $50 \%$ of cells). ${ }^{10}$ In this group of CLL/PL the membrane phenotyping markers showed a closer affinity to CLL than to PLL, such as a high percentage of M-rosettes, constant positivity with CD5, and low reactivity with FMC7. In our group of INT lymphomas the membrane markers were different from those of typical CLL and CLL/PL because they had no affinity to form M-rosettes (only two out of nine cases), SmIg was strongly expressed, FMC was positive in most cases, and CD10 was positive in some. No single case of INT lymphoma had the fulto phenotype commonly seen in B-CLL.

INT lymphoma is a form of low grade NHL, initially designated as such because the cells were intermediate in appearance between the small round lymphocytes of "well differentiated lymphocytic lymphoma/chronic lymphocytic leukaemia" and the angulated and abnormal lymphocytes of "poorly differentiated lymphocytic lymphoma"." Early reports speculated that the cells might be related to the lymphocytes of the follicular lymphoid cuff based on enzyme cytochemistry and morphological characteristics, such as the presence of residual naked germinal centres often seen within affected lymph nodes. ${ }^{12}$ The term "mantle zone lymphoma" was first coined for those cases with an exclusive mantle zone pattern of growth ${ }^{13}$ but it has also been used as a synonym for INT lymphoma.' Several authors have noted the phenotypic and morphological similarities between INT and centrocytic lymphomas in the Kiel classification, ${ }^{3}$ both of which are distinct from follicular or centrocytic/centroblastic lymphomas. ${ }^{45}$ Harris and Bhan questioned the specificity of a mantle zone pattern of growth with neoplastic cells surrounding normal germinal centres, ${ }^{14}$ but in fact several of their cases did not exhibit a mantle zone pattern of growth with neoplastic cells surrounding normal germinal centres, but represented follicular lymphomas (cases 5-8) in which neoplastic nodules mimicked normal 
follicles to a greater than normal degree. ${ }^{14}$ Notably, all those cases had a phenotype typical of follicular lymphoma-monoclonal B cell, CD5 negative. Three of four were also B2 (or CD21) positive. As these authors correctly noted, however, the phenotype of normal mantle zone B cells is not fully recapitulated in mantle zone or INT lymphomas, because mantle zone cells are normally CD5 negative. INT and centrocytic lymphomas are consistently CD5 positive, as were all cases in our series. Centrocytic lymphomas and INT are clearly closely related morphologically and phenotypically, but may not be entirely interchangeable pathological entities.

According to published data, ${ }^{1516}$ INT lymphoma expresses SmIg and B cell associated antigens Ia, CD19, CD22 and CD20, CD5, and a variable percentage of cases are also CD10. The expression of CD10 in INT lymphoma has been a controversial issue because it has been reported as negative by some authors, suggesting a difference with follicular lymphoma. ${ }^{1317}$ According to these studies, follicular lymphoma arises from a cell that is a normal constituent of follicular centres (CD10+) and INT NHL arises from the lymphocytic corona (CD10-). Cossman et al, however, reported the positive expression of the CALL antigen (CD10) on most cases of INT NHL, in which lymph node cell suspensions were studied using flow cytometry. ${ }^{5}$ Our findings using viable cell suspensions also indicate that the CD10 antigen can often be shown in INT lymphoma. The difference from the findings of other studies reflects the different techniques used because negative results have mainly been recorded using frozen sections tested by immunohistochemistry, which may fail to detect a weak expression of this antigen. ${ }^{4} 1516$

A characteristic feature of INT NHL, like B-CLL, is the expression of CD5, as we have seen in our results. This feature was also seen in the five cases classified as small lymphocytic lymphoma with cleaved cells. Table 4 summarises the immunological profile of INT NHL compared with that of other closely related B cell disorders. INT NHL has a distinctive profile which suggests an intermediate stage with a close relationship to follicular centre cell lymphoma, small lymphocytic lymphoma, and B-CLL. The five cases which were not regarded as typical INT NHL by histological analysis, nor typical B-CLL by peripheral blood morphology, were also indeterminable by membrane phenotype. While three cases were characteristic of INT NHL, two cases more closely resembled B-CLL. Such cases also differed from typical INT cases in the appearance of the peripheral blood films which contained cells that wrere predominantly small with few pleomorphic features. Histologically, small lymphocytic lymphoma with cleaved cells principally differed from INT NHL because of pseudofollicular
Table 4 Markers in circulating cells of NHL in leukaemic phase and $B-C L L$

\begin{tabular}{lllll}
\hline Markers & $C L L$ & CLL/PL & INT* & $\begin{array}{l}\text { Follicular } \\
\text { lymphoma }\end{array}$ \\
\hline SmIg & $+1-$ & $-1++$ & ++ & ++ \\
M-rosettes & ++ & ++ & $+1-$ & - \\
CD5 & ++ & ++ & ++ & - \\
FMC7 & - & $-1+$ & ++ & ++ \\
CD10 & - & $-1+$ & $-1+$ & ++ \\
\hline
\end{tabular}

*Includes centrocytic lymphoma.

growth centres containing prominent prolymphocytes and the absence of cells with finely distributed or "blastic" chromatin. Despite the differences recorded in histology, peripheral blood picture, and phenotype, conclusive evidence that these cases correspond to INT NHL or to CLL was absent. Perhaps the application of molecular genetic or cytogenetic markers may allow such cases to be appropriately classified in future.

It is concluded that by combining histology, membrane markers, and peripheral blood morphology, the leukaemic phase of typical INT lymphoma can be defined in most cases. It is difficult, with a small series, to draw definitive conclusions about the natural history of the disease or the prognostic importance of a leukaemic phase in INT lymphoma. It is worth noting, however, that half of the patients (four of eight) for whom follow up information was available died in less than two years, a feature also observed in cases of follicular lymphoma presenting with a high white cell count. ${ }^{6}$ Although the numbers are small, those cases classified as small lymphocytic lymphoma with cleaved cells seem to have a somewhat better prognosis, closer to that of classic B-CLL.

We are grateful to the following colleagues who referred samples and slides from patients under their study: Drs S Davies, G Markey, S Fairhead, DW Milligan, TCM Morris, J Reeve and JH Robertson. We are also grateful to Dr Sudha Rani, who helped with the immunological analysis of some samples. Professor Garrido-Torres provided GRBI, anti-class II MHL antigen; Dr P Beverley donated UCHT2 (CD5), anti-p67; and CLB/BLYT, anti-p135 (CD22) was donated by Dr von Dem Borne.

\section{References}

1 Jaffe ES, Bookman MA, Longo DL. Lymphocytic lymphoma of intermediate differentiation. Mantle zone lymphoma: a distinct subtype of B-cell lymphoma. Hum Pathol 1987;18:877-80.

2 Rosenberg SA, Berard CW, Brown BW, et al. National Cancer Institute sponsored study of classifications of non-Hodgkin's lymphomas. Cancer 1982;49:2112-35.

3 Lennert K. Malignant lymphomas other than Hodgkin's disease. Berlin: Springer-Verlag, 1978:302-46. 
4 Swerdlow SH, Habeshaw JA, Murray LJ, Dhaliwal HS, Lister TA, Stansfeld AG. Centrocytic lymphoma: a distinct clinicopathological and immunological entity. Am J Pathol 1983;113: 181-97.

5 Cossman J, Neckers LM, Hsu SM, Longo DL, Jaffe ES. Low grade lymphomas, expression of developmentally regulated Bcell antigens. Am J Pathol 1984;115:117-24.

6 Melo JV, Robinson DS, Oliveira MSP, et al. Morphology and immunology of circulating cells in leukaemic phase of follicular lymphoma. J Clin Pathol 1988;41:951-9.

7 Melo JV, Catovsky D, Galton DAG. The relationship between chronic lymphócytic leukaemia and prolymphocytic leukaemia. Clinical and laboratory features of 300 patients and characterisation of an intermediate group. $\mathrm{Br} J$ Haematol 1986;63: 377-87.

8 Galton DAG, Goldman JM, Wiltshaw E, Catovsky D, Henry K, Goldenberg GJ. Prolymphocytic leukaemia. Br J Haematol 1974;27:7-23

9 Weisenburger DD, Nathwani BN, Diamond LW, Windberg CD, Rappaport H. Malignant lymphoma, intermediate lymphocytic type: a clinicopathologic study of 42 cases. Cancer 1981; 48:1415-25.

10 Melo JV, Catovsky D, Galton DAG. Chronic lymphocytic leukaemia: a clinicopathologic reappraisal. Blood Cells 1987;12:339-53.

11 Berard CW, Dorfman RF. Histopathology of malignant lymphomas. Clin Haematol 1974;3:39.
12 Jaffe ES, Braylan RC, Nanba K, et al. Functional markers: A new perspective on malignant lymphomas. Cancer Treat Rep 1977; 61:953.

13 Weisenburger DD, Kim H, Rappaport H. Mantle zone lymphoma: a follicular variant of intermediate lymphocytic lymphoma. Cancer 1982;49:1429-38.

14 Harris NL, Bhan AK. Mantle zone lymphoma. A pattern produced by lymphomas of more than one cell type. Am J Surg Pathol 1985;9:872-82.

15 van den Ooad JJ, de Wolf DC, Pulford KAF, Mason DY, Desmet VJ. Mantle zone lymphoma: immuno- and enzymohistochemical studies on the cell. Am J Surg Pathol 1986;10:780-8.

16 Weisenburger DD, Sanger WG, Armitage JO, Purtillo DT. Intermediate lymphocytic lymphoma: immunophenotypic and cytogenetic findings. Blood 1987;69:1617-21.

17 Harris NL, Nadler LM, Blank AK. Immunohistologic characterisation of two malignant lymphomas of germinal center type (centroblastic/centrocytic and centrocytic) with monoclonal antibodies. Follicular and diffuse lymphoma of small cleaved type are related but distinct entities. Am J Pathol 1984;117: $262-72$.

Requests for reprints to: Professor D Catovsky, Department of Haematology and Cytogenetics, The Royal Marsden Hospital, Fulham Road, London SW3 6JJ, England. 